\title{
Initiation of anti-osteoporotic drugs in high-risk female patients starting glucocorticoid treatment: a population study in Norway
}

\author{
Ellen M. Apalset ${ }^{1,2} \cdot$ Astrid Lunde $^{1}$ (1) $\cdot$ Mari Hoff $^{3,4,5} \cdot$ Vera Ehrenstein $^{6} \cdot$ Grethe S. Tell $^{1}$
}

Received: 9 February 2020 / Accepted: 1 July 2020 / Published online: 5 August 2020

(C) The Author(s) 2020

\begin{abstract}
Summary Glucocorticoid use is a risk factor for osteoporosis and fractures. We studied whether women initiating glucocorticoid treatment also started anti-osteoporotic treatment, according to clinical guidelines. Women with versus without previous fracture were twice as likely to start anti-osteoporotic treatment within 1 year after initiating glucocorticoid treatment, but the cumulative incidences were low $9.1 \%$ vs. $4.6 \%$, respectively.

Purpose Use of glucocorticoids (GC) is a risk factor for osteoporosis and fractures, and clinical guidelines suggest that preventive treatment with anti-osteoporotic drugs (AOD) should be considered when starting GC. Women with high risk of osteoporosis comprise those with previous fractures or a known inflammatory rheumatic disease, for whom the indication of AOD is even stronger. The purpose of these analyses was to investigate whether women initiating GC treatment also started AOD, especially those with high risk of osteoporosis.

Methods We used data from the Norwegian Prescription Database to identify all women 55 years and older initiating GC treatment in Norway during 2010-2016 and to obtain information on use of AOD. Data from the Norwegian Patient Registry were used to obtain information on previous fractures and diagnoses.

Results Among 105,477 women initiating GC treatment during 2010-2016, 3256 had started AOD and 79,638 had discontinued GC treatment after 1-year follow-up. Cumulative incidence of starting AOD after 1 year was 9.1\% (95\% CI: 7.9, 10.4) for women with vs. $4.6 \%$ (95\% CI: $4.4 \%, 4.8 \%$ ) for women without a previous fracture. Women with rheumatoid arthritis or another inflammatory rheumatic disease were more likely to start AOD than women with other indications. For the whole cohort, the probability of starting AOD treatment within 1 year after initiating GC increased on average $3 \%$ per year (HR $=1.03$, CI: 1.01 , 1.05) from 2010 to 2016.

Conclusions Having had a previous fracture or an inflammatory rheumatic disease increased the probability of treatment with AOD. However, the proportions starting AOD were much lower than clinically indicated.
\end{abstract}

Keywords Glucocorticoids $\cdot$ Anti-osteoporotic drugs $\cdot$ Osteoporosis $\cdot$ Fracture $\cdot$ Inflammatory rheumatic diseases

Electronic supplementary material The online version of this article (https://doi.org/10.1007/s11657-020-00783-8) contains supplementary material, which is available to authorized users.

Astrid Lunde astrid.lunde@uib.no

1 Department of Global Public Health and Primary Care, University of Bergen, Kalfarveien 31, N-5018 Bergen, Norway

2 Bergen Group of Epidemiology and Biomarkers in Rheumatic Disease, Department of Rheumatology, Haukeland University Hospital, Bergen, Norway
3 Department of Neuromedicine and Movement Science, NTNU Norwegian University of Science and Technology, Trondheim, Norway

4 Department of Public Health and Nursing, NTNU - Norwegian University of Science and Technology, Trondheim, Norway

5 Department of Rheumatology, St. Olavs University Hospital, Trondheim, Norway

6 Department of Clinical Epidemiology, Aarhus University, Aarhus, Denmark 


\section{Introduction}

Glucocorticoids (GCs) are part of the standard treatment in many conditions including inflammatory, autoimmune, and allergic diseases, cancer, and organ transplantations. Prescription of long-term therapy with GC (3 months or more) has been increasing, and around 1\% of the population (19982008) of the UK were treated with GC [1]. Major side effects include osteoporosis and fractures. Use of GC is the most common cause of secondary osteoporosis $[2,3]$, and 30 $40 \%$ of all patients treated with GC have radiological evidence of vertebral fractures $[4,5]$. Risk of bone loss and fracture rises rapidly after $\mathrm{GC}$ treatment initiation [6-8]. In addition, for persons with similar bone mineral density (BMD), the risk of vertebral fractures is larger for GC users than for nonusers [9], indicating an additional effect on bone quality. The harmful effects on bone are dose-dependent, but no safe dose limit has been established [8].

According to both older and newer guidelines in Europe and the USA, the threshold for starting preventive treatment with anti-osteoporotic drugs (AOD) after initiation of GC medication should be low. This applies especially to highrisk patients (e.g., those with a history of low-energy fracture) or if GC therapy is intended to last for more than 3 months [10-12]. These recommendations were also implemented in the guidelines from the Norwegian Society of Rheumatology in 2015 [13]. However, overall use of AOD in Norway is lower than in other European countries [14-16]: in a Norwegian study, only $22.5 \%$ of women already receiving $\mathrm{GC}$ were treated with AOD during the first year after a forearm fracture [15]. Another Norwegian study found that use of AOD was highest in areas with the historically lowest incidence of osteoporotic fractures [17]. This indicates that, among those at highest risk of suffering a fracture, a suboptimal proportion receives anti-osteoporotic treatment.

GCs have for several decades been an important part of therapy in several inflammatory rheumatic diseases; patients with rheumatoid arthritis (RA), for example, may receive GC over many years $[18,19]$. Treatment with GC may have a bone protective effect in highly inflammatory states [20], and the majority of newly diagnosed RA patients are treated with GC in the early stages to achieve rapid disease remission [21]. Both the disease and the treatment with GC are potentially harmful to the bone, and RA is the only medical condition considered to be a separate risk factor in the fracture risk assessment tool FRAX® [22]. There has been increasing emphasis on limiting use of GC to short periods and in moderate doses [23], but studies have not found a reduced use of GC in patients with RA $[1,19]$. Another inflammatory rheumatic disease, giant cell arteritis (GCA), requires high doses and often long-term treatment with GC due to risk of serious complications including blindness if not adequately treated. Until recently, there has been no alternative treatment to GC for this condition, and in Norway, GC is still preferred due to low economical costs. Polymyalgia rheumatica (PMR), despite being commonly regarded as a disease with low morbidity, is one of the most common indications for starting GC [1]. Because PMR patients are often older than patients with RA at disease onset, they have a higher prevalence of previous fractures [24]. In addition, many of them sustain new fractures during GC treatment [24]. Even though the risk of osteoporosis and fractures due to long time GC therapy is substantial, the attentiveness to osteoporosis prophylaxis has been low [25].

Although treatment guidelines are clear and most physicians are aware of the detrimental effect of GC on bone, the degree to which these guidelines are adhered to in clinical practice is not clear. Thus, our primary aim was to examine the initiation of osteoporosis prophylaxis with AOD in women starting treatment with oral GC. We further investigated whether high-risk groups, i.e., women with a history of fracture or a rheumatic inflammatory disease, were more likely to receive AOD after starting GC. Finally, we examined changes in the prescribing rates of AOD at GC initiation from 2010 to 2016.

\section{Methods}

\section{Study design and study population}

This was a nationwide cohort study using data from the National Registry of Norway [26], the Norwegian Prescription Database (NorPD) [27, 28], the Norwegian Patient Registry (NPR) [29], the Norwegian Cause of Death Registry [30], and the Norwegian Education Database [31]. In Norway, every resident is assigned a unique identification number which enables exact linkage of each individual's data from various registries. Government-funded hospitals and specialty clinics are required to report to the NPR, and diagnoses from all in- and outpatient hospital encounters have been recorded since 2008 [32]. The Norwegian Cause of Death Registry provides information on deaths and has high completeness [33]. The NorPD contains information on all prescription dispensings at outpatient pharmacies, ordered by physicians in both primary and specialist health care.

The source population consisted of 1,004,067 Norwegian women aged 55 years or older registered in the National Registry of Norway during 2010-2016. The study population consisted of all women initiating GC treatment (GC naïve), defined as having at least one GC dispensing from an outpatient pharmacy during the study period and with no dispensings during a 5-year look-back period. Prednisolone is the most commonly used GC outpatient treatment regimen, while prednisone is not a registered drug in Norway. Only systemic GC was studied (Table S1/Supplementary). 
Only AOD naïve women initiating GC were included, excluding prevalent AOD users at the onset of GC treatment (5year look-back) (Fig. 1). We expected a high proportion of women 85 years or older to live in nursing homes, and medication administered there are not registered in the NorPD; thus, women aged $85+$ years at GC initiation treatment were excluded. Finally, women initiating GC treatment due to palliative care in cancer were excluded (identified through reimbursement codes, described below). The study population thus included 105,477 AOD naïve women (55-84 years) starting GC treatment, with follow-up through 2017.

\section{Time at risk}

A patient was considered at risk of starting AOD treatment from the date of the first $\mathrm{GC}$ dispensing until discontinuation of GC treatment, the latter defined as a period without a new GC dispensing of 180 days or longer (grace period) beyond what was expected based on the days supplied in the lastrecorded GC dispensing. Impact of the chosen grace period was examined in a sensitivity analysis where the grace period was changed to 90 days.

\section{Exposure}

Fracture diagnoses for the hip, femur, ulna, radius, spine, pelvis, and humerus were obtained in the 2-year pre-GC baseline period and used as the exposure in the analyses (Table S2/ Supplementary).

In Norway, GC treatment for certain diagnoses is reimbursed through governmental funding (i.e., at no, or low, cost for the patient). Such reimbursement diagnosis codes were used to identify the underlying disease ("GC indications," Table S3). Reimbursement diagnosis code belonging to the first GC dispensing were categorized into four indication groups and used as exposure: "rheumatoid arthritis," "other inflammatory rheumatic disease," "other indications," and "indication not known" (supplementary Table S3). Women without reimbursement at first GC dispensing $(60 \%)$ or with reimbursement but with missing reimbursement diagnosis
Fig. 1 Norwegian women 5584 years old initiating glucocorticoid (GC) treatment during 2010-2016. Flowchart of study population with inclusion and exclusion criteria

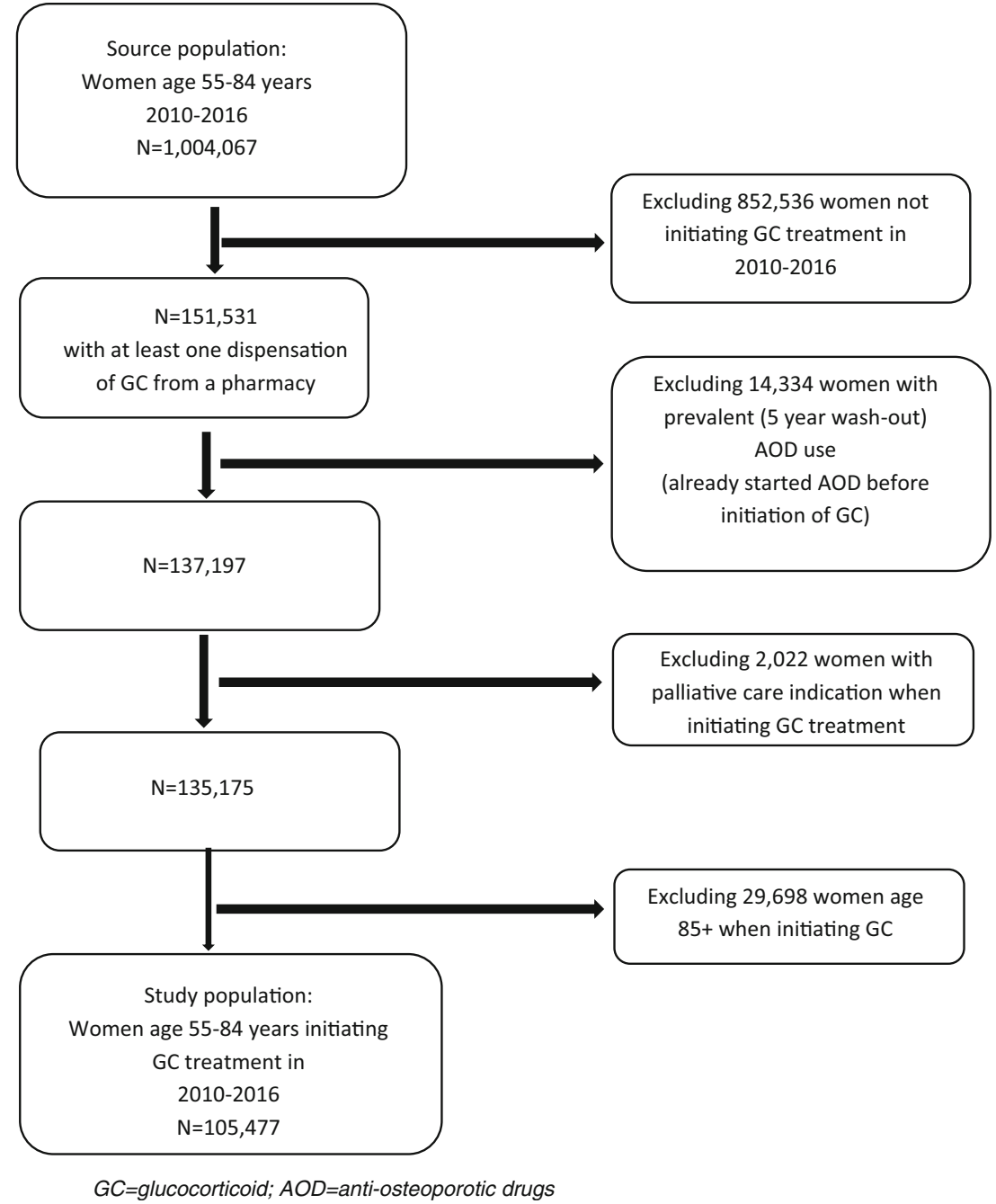


code $(5 \%)$ were categorized according to the ICD-10 diagnoses that could be indications for GC treatment, obtained from the NPR during the 2-year baseline period. In case of more than one potential indication, the most recent diagnosis relative to the first GC dispensing was used. The category "other indications" includes chronic obstructive lung disease, asthma, sarcoidosis, dermatitis, and ulcerative colitis (Table S4/ Supplementary).

\section{Outcome}

The time from the first GC dispensing until the first dispensing of AOD was used as the outcome in the analyses, treating discontinuation of the GC treatment as a censoring event, death as a competing event (cumulative incidence) or censoring event (Cox regression), and emigration or end of the study period (31 December 2017), whichever came first, as censoring events. AOD included in the study are listed in Table S1 (Supplementary).

\section{Covariates}

Diagnoses describing comorbidity were obtained according to the Romano modification of the Charlson comorbidity index (CCI) $[29,34]$. This modification differs from the original $\mathrm{CCI}$ in that it includes dementia but excludes HIV. It further includes inflammatory rheumatic disease categories (connective tissue disease) such as rheumatoid arthritis, GCA, systemic lupus erythematosus (SLE), dermatopolymyositis, systemic sclerosis, and PMR. Information on relevant drug use (except GC and AOD) was collected for each woman in the 2-year baseline period preceding GC initiation. We did not adjust for $\mathrm{CCI}$ in the final analysis, as this only altered the associations slightly.

Education, age, and year at GC initiation were all adjusted for in the Cox regression analyses. Information on highest achieved education was obtained from the Norwegian Education Database [35] and categorized into basic (compulsory), secondary (high school/vocational education), or tertiary (college or university).

\section{Statistical analyses}

Distributions of continuous variables were reported as medians and interquartile ranges; categorical variables were summarized using counts and percentages. Cumulative incidence of initiating AOD was calculated using the Aalen-Johansen method for competing risk, treating death as a competing event, stratified by having a history of fracture, among all women initiating GC and among women with known indication for GC treatment, stratified by GC indication, and stratified by Defined Daily Dose (DDD) of GC initially given (< 90 DDD and $>=90$ DDD). Due to the low number of patients at risk after 5-year follow-up, we used 5 years as the maximum follow-up when calculating cumulative incidence.

Cox regression was used to estimate associations (HRs) between women with versus without a previous fracture and initiation of AOD at 1-year follow-up, stratified by GC indication and by DDD of GC initially given. In this analysis, death and termination of GC treatment were treated as censoring events. Analyses were adjusted for age at the index date (5-year age groups) and year initiating GC (linear term) and education. Due to few GC naïve patients with a previous fracture starting AOD treatment after 1-year GC treatment, we only present hazard ratios for fracture versus no previous fracture for starting AOD within 1 year after $\mathrm{GC}$ treatment and not for longer follow-up periods.

Age-standardized incidence rates of initiating AOD within 1 year from start of GC treatment were calculated using the direct method with 5-year age intervals using all women 5584 years in Norway as the standard, treating discontinuation of GC treatment, death, and emigration as censoring events.

We calculated time trends of initiating AOD within 1 year of starting GC treatment, calculating hazard ratios using Cox regression, adjusting for age and education. We tested for possible interactions between time trend and GC indication and with previous fracture.

In all analyses, 95\% confidence intervals (CIs) were calculated, and all analyses were conducted using $\mathrm{R}$.

\section{Ethics}

The study was approved by the Regional Committee for Medical and Health Research Ethics and by the Norwegian Data Protection Authority.

\section{Results}

Baseline characteristics of the study population are presented according to a 2-year pre-baseline history of fracture (Table 1). About $3.7 \%$ of the study population had a fracture before initiation of GC, and the women in this group were older, and they had a higher comorbidity in most disease categories and a higher CCI score than women without fracture. Use of immunosuppressant medication other than GC was slightly higher for the fracture group. Women without a previous fracture had higher educational level than women with a fracture. While $3.0 \%$ in the total cohort had a diagnosis of rheumatoid arthritis registered in the NPR, $8.6 \%$ in the no fracture group and $8.8 \%$ in the previous fracture group had a rheumatoid arthritis reimbursement code from the primary or the specialist health care at the first GC dispensing.

Women with and without previous fracture had similar amount of reimbursement at their first GC dispensing, $41 \%$ versus $37 \%$, respectively. Among those with reimbursement, 
the majority had a known reimbursement code (known indication) (Table 1).

A total of 4504 women started AOD during follow-up (minimum 1 year and maximum almost 8 years), where 3256 women had started AOD and 79,638 were censored after 1-year follow-up. Among women with rheumatoid arthritis or other inflammatory rheumatic disease, $50 \%$ had discontinued GC treatment after 1-year follow-up versus $80 \%$ among women with other GC indications and $86 \%$ with no known GC indication. Among women who started AOD treatment (and without a GC treatment gap of more than 180 days), median time between the first GC and the first AOD prescription dispensation was 592 days (interquartile range (IQR): 203, 1209) for women without a previous fracture and 417 days (IQR: 149, 944) among women with a previous fracture.

Cumulative incidence of starting AOD was higher at any time point among women with versus without a previous fracture. This was true both for women with known GC indication and among all women (Fig. 2). Further, cumulative incidence of starting AOD at 1-year follow-up was slightly higher among women with a known GC indication compared with all women, both for women with previous fracture and no fracture, and this difference persisted through the 5-year follow-up (Fig. 2). Among all women initiating GC, the cumulative incidence of starting AOD within 1 year was $9.1 \%$ (95\% CI: $7.9,10.4)$ among women with fracture versus $4.6 \%$ (95\% CI: $4.4 \%, 4.8 \%$ ) among those without fracture (Fig. 2). After 5 -year follow-up, cumulative incidence was $30.2 \%$ (95\% CI: $23.8 \%, 36.5 \%$ ) among women with fracture versus $23.2(95 \%$ CI: $21.9 \%, 24.5 \%$ ) among women without.

Among women with known indication for GC treatment, the cumulative incidences at 1-year follow-up were $11.8 \%$ (95\% CI: $10.0,13.5)$ for women with a fracture and $7.1 \%$ (95\% CI: 6.8, 7.4) without fracture (Fig. 2).

Cumulative incidences of receiving AOD within 1 year after initiation of GC treatment among women with rheumatoid arthritis and other inflammatory rheumatic diseases were $10.1 \%$ (95\% CI: 9,5, 10.8) and $13.3 \%$ (95\% CI: 12.5, 14.1), respectively. This was 2-3 times higher (and decreasing over time) than for women with other indications and for indication not known (cumulative incidence 3.6 (95\% CI: 3.2, 3.9) and 2.4 (95\% CI: 2.2, 2.7), respectively) (Fig. 3, left). After 5-year follow-up, the cumulative incidences were $30.6 \%$ for rheumatoid arthritis, $30.4 \%$ for other inflammatory rheumatic disease, $21.6 \%$ for other indications, and $18.8 \%$ for indication not known.

Cumulative incidence of receiving AOD within 1 year after initiation of GC treatment was higher among women receiving an initial dose of GC of more than 90 DDD for any indication, and this difference was highest among women with other inflammatory rheumatic diseases (Fig.3, right). A majority of women received an initial dose of less than 90 DDD, and a high proportion of these continued GC treatment beyond 1 year.
The higher 1-year probability of receiving AOD in the fracture group persisted after adjusting for baseline covariates (age, education, and year of initiation of GC), with a HR of 2.0 (95\% CI: 1.8, 2.3) (Table 2). Among women with rheumatoid arthritis or another inflammatory rheumatic disease as indication for GC treatment, the probability of starting AOD within 1 year was 1.5-1.6 times higher when having had a previous fracture versus no fracture (Table 2). Among women with other known indications for GC treatment and for women with no known indication for GC treatment, the difference between the fracture and no fracture group was 2.4-2.6-fold (Table 2). Stratifying on initial dose of GC gave slightly higher HR for DDD $<90$ compared with DDD $>=90$ for fracture vs. no fracture group (Table 2).

Age-standardized incidence rates of starting AOD within 1 year after initiating GC showed an increasing trend in the period 2010-2016 for all studied GC indications (Fig.4). Adjusting for age and education, the 1-year probability of receiving $\mathrm{AOD}$, among all women initiating $\mathrm{GC}$, increased on average $3 \%$ per year $(\mathrm{HR}=1.03, \mathrm{CI}: 1.01,1.05)$ from 2010 to 2016. For those with rheumatoid arthritis as indication for $\mathrm{GC}$ treatment, the yearly increase was $3 \%(\mathrm{HR}=1.03$, CI: $1.00,1.07)$; for other inflammatory rheumatic diseases, the increase was $4 \%(\mathrm{HR}=1.04, \mathrm{CI}: 1.01,1.07)$, for other indications $7 \%(\mathrm{HR}=1.07, \mathrm{CI}: 1.02,1.11)$, and for no known indication $3 \%(\mathrm{HR}=1.05 ; 1.03,1.07)$. Among women with previous fracture, the increase was $10 \%$ per year $(\mathrm{HR}=1.10, \mathrm{CI}$ : $1.03,1.17)$. There was no significant interaction between these time trends and type of GC indication or with fracture status.

\section{Sensitivity analysis}

Repeating the analyses reducing the grace period from 180 to 90 days before censoring patients yielded slightly lower HRs for receiving AOD at 1-year follow-up for women with fracture vs. no fracture (Table 2, 180 days). Cumulative incidences of starting AOD within 1 year increased from 10.1 to $11.6 \%$ for rheumatoid arthritis, from 13.1 to $15.4 \%$ for other inflammatory rheumatic diseases, from 3.6 to $5.3 \%$ for other indications, and from 2.4 to $4.2 \%$ for indication not known. The corresponding cumulative incidences at 5-year follow-up were $37 \%, 36 \%, 27 \%$, and $26 \%$ for these GC indications, respectively.

\section{Discussion}

\section{Summary}

Among postmenopausal women starting GC therapy, those who had suffered a fracture during the previous 2 years were twice as likely to start treatment with AOD than women 
Table 1 Baseline characteristics of Norwegian women (5584 years) starting treatment with glucocorticoids (GC) in the period 2010-16, stratified by previous fracture registered in a 2-year look-back period before starting GC treatment $(N=105,477)$

\begin{tabular}{|c|c|c|}
\hline & $\begin{array}{l}\text { Previous fracture } \\
(N=3899)\end{array}$ & $\begin{array}{l}\text { No previous fracture } \\
(N=101,578)\end{array}$ \\
\hline & Number $(\%)$ & \\
\hline Median age (years) at initiation of GC (IQR) & $70(63,77)$ & $67(61,74)$ \\
\hline \multicolumn{3}{|l|}{ Age at initiation of GC $(N, \%)$} \\
\hline $55-64$ years & $1116(28.6)$ & $40,186(39.6)$ \\
\hline $65-74$ years & $1402(36.0)$ & $37,391(36.8)$ \\
\hline $75-84$ years & $1381(35.4)$ & $24,001(23.6)$ \\
\hline \multicolumn{3}{|l|}{ Year starting GC treatment $(N, \%)$} \\
\hline 2010 & $499(12.8)$ & $13,672(13.5)$ \\
\hline 2011 & $573(14.7)$ & $13,901(13.7)$ \\
\hline 2012 & $593(15.2)$ & $14,901(14.7)$ \\
\hline 2013 & $601(15.4)$ & $14,637(14.4)$ \\
\hline 2014 & $560(14.4)$ & $15,176(14.9)$ \\
\hline 2015 & $548(14.1)$ & $14,926(14.7)$ \\
\hline 2016 & $525(13.5)$ & $14,365(14.1)$ \\
\hline \multicolumn{3}{|c|}{ Number of Defined Daily Doses dispensed of GC at initiation of GC $(N, \%)$} \\
\hline$<90 \mathrm{DDD}$ & $3519(90.3)$ & $92,368(90.9)$ \\
\hline$>=90 \mathrm{DDD}$ & $380(9.7)$ & $9210(9.1)$ \\
\hline \multicolumn{3}{|l|}{ Education $(N, \%)$} \\
\hline Basic (compulsory) & $1320(33.9)$ & $32,487(32.0)$ \\
\hline Secondary (high school/vocational) & $1877(48.1)$ & $48,500(47.7)$ \\
\hline Tertiary (college/university) & $658(16.9)$ & $19,429(19.1)$ \\
\hline Unknown/missing & $44(1.1)$ & $1162(1.1)$ \\
\hline \multicolumn{3}{|l|}{ CCI score $(N, \%)$} \\
\hline 0 & $2292(58.8)$ & $71,907(70.8)$ \\
\hline $1-2$ & $932(23.9)$ & $20,279(20.0)$ \\
\hline $3+$ & $675(17.3)$ & $9392(9.2)$ \\
\hline \multicolumn{3}{|l|}{ Comorbidity categories $^{\mathrm{a}}(\mathrm{N}, \%)$} \\
\hline Myocardial infarction & $240(6.2)$ & $3939(3.9)$ \\
\hline Congestive heart failure & $187(4.8)$ & $2005(2.0)$ \\
\hline Peripheral vascular disease & $132(3.4)$ & $2244(2.2)$ \\
\hline Cerebrovascular disease & $222(5.7)$ & $2709(2.7)$ \\
\hline Dementia & $68(1.7)$ & $390(0.4)$ \\
\hline Chronic pulmonary disease & $654(16.8)$ & $9957(9.8)$ \\
\hline $\begin{array}{l}\text { Connective tissue disease/inflammatory rheu- } \\
\text { matic disease }^{\mathrm{b}}\end{array}$ & $217(5.6)$ & $4567(4.5)$ \\
\hline Rheumatoid arthritis & $157(4.0)$ & $3033(3.0)$ \\
\hline Giant cell arteritis & $14(0.4)$ & $235(0.2)$ \\
\hline Systemic lupus erythematosus & $6(0.2)$ & $220(0.2)$ \\
\hline Dermatopolymyositis & $1(0.0)$ & $56(0.1)$ \\
\hline Polymyalgia rheumatica & $43(1.1)$ & $1088(1.1)$ \\
\hline Systemic sclerosis & $6(0.2)$ & $96(0.1)$ \\
\hline Ulcer disease & $59(1.5)$ & $760(0.7)$ \\
\hline Mild liver disease & $33(0.8)$ & $534(0.5)$ \\
\hline Diabetes & $321(8.2)$ & $5655(5.6)$ \\
\hline Diabetes with end organ damage & $141(3.6)$ & $1884(1.9)$ \\
\hline Hemiplegia & $14(0.4)$ & $127(0.1)$ \\
\hline Moderate or severe renal disease & $117(3.0)$ & $1710(1.7)$ \\
\hline Any tumor, leukemia, lymphoma & $454(11.6)$ & $10,162(10.0)$ \\
\hline Moderate or severe liver disease & $18(0.5)$ & $132(0.1)$ \\
\hline
\end{tabular}


Table 1 (continued)

\begin{tabular}{lll}
\hline & $\begin{array}{l}\text { Previous fracture } \\
(N=3899) \\
\text { Number }(\%)\end{array}$ & $\begin{array}{l}\text { No previous fracture } \\
(N=101,578)\end{array}$ \\
& $121(3.1)$ & $2262(2.2)$ \\
\hline Metastatic solid tumor & & $6982(6.9)$ \\
Other drug use $(N, \%)$ & $306(7.8)$ & $25,612(25.2)$ \\
Blood glucose lowering drugs, excluded insulins & $759(19.5)$ & $3738(3.7)$ \\
Hormone replacement therapy & $185(4.7)$ & $2326(2.3)$ \\
Immunosuppressant drugs & $149(3.8)$ & $29,001(28.6)$ \\
Insulin and analogues & $1252(32.1)$ & $8699(8.6)$ \\
Proton pump inhibitor & $342(8.8)$ & $6543(6.4)$ \\
Reimbursement according to NorPD (ICPC code & or ICD-10 code $\left.{ }^{\mathrm{d}}\right)(N, \%)$ \\
Rheumatoid arthritis & $269(6.9)$ & $17,439(17.2)$ \\
Other inflammatory rheumatic disease & $772(19.8)$ & $4702(4.6)$ \\
Other indication & $214(5.5)$ & \\
Indication not known & & $470(0.5)$ \\
Indication according to NPR ${ }^{\mathrm{e}}(N, \%)$ & $32(0.8)$ & $2124(2.1)$ \\
Rheumatoid arthritis & $211(5.4)$ & $6762(6.7)$ \\
Other inflammatory rheumatic disease & $365(9.4)$ & \\
Other indication & &
\end{tabular}

$I Q R$ interquartile range, $D D D$ Defined Daily Dose, $C C I$ Romano modification of the Charlson comorbidity index Women already treated with anti-osteoporotic drugs when starting GC were excluded (5 years look-back)

${ }^{a}$ According to Charlson comorbidity index (CCI), Romano modification

${ }^{\mathrm{b}}$ Connective tissue disease is the term used in CCI, commonly used term is rheumatic inflammatory diseases

${ }^{\mathrm{c}}$ Reimbursement code associated with first dispensing of GC (primary care). International Classification of Primary Care (ICPC)

${ }^{\mathrm{d}}$ Reimbursement code associated with first dispensation of GC (specialist health care). International Statistical Classification of Diseases and Related Health Problems, 10th revision (ICD-10)

${ }^{\mathrm{e}}$ Patient with indication according to the NPR (and no indication in NorPD at first GC dispensing) in the 2-year baseline period. If more than one relevant diagnosis, the one closest in time before first GC dispensing was chosen

Women initiating AOD (With known GC indication)

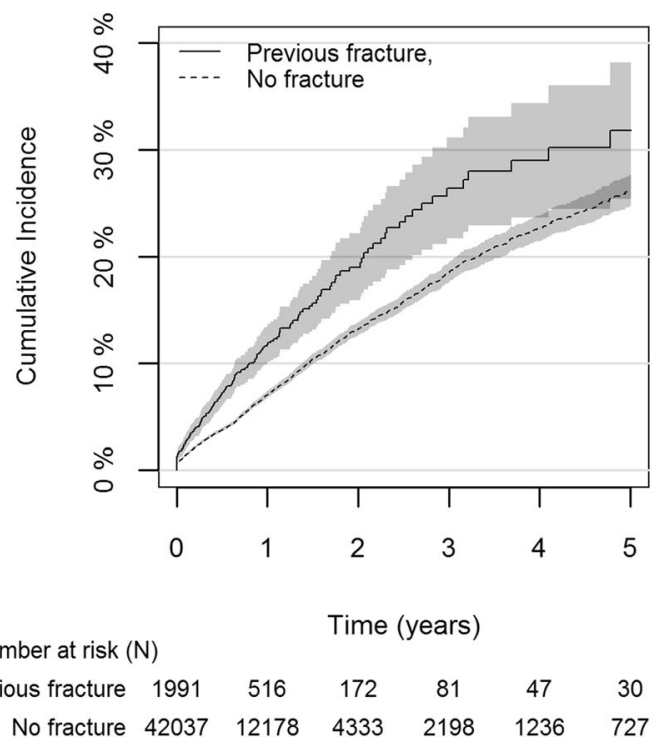

Fig. 2 Cumulative incidence (with $95 \%$ confidence bands) of women starting treatment with anti-osteoporotic drugs (AOD) after initiation of glucocorticoid (GC) treatment 2010-2016, stratified by having had a previous fracture or not during the previous 2 past years. The figure to

\section{Women initiating AOD}

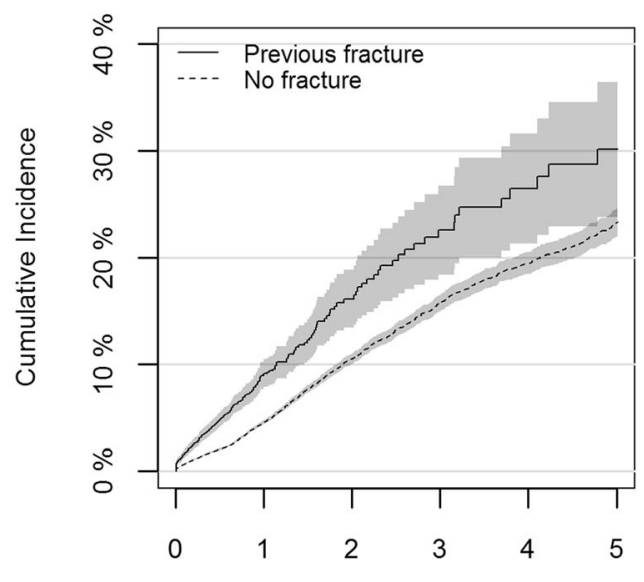

Time (years)

\begin{tabular}{rcccccc} 
Number at risk (N) & \multicolumn{1}{l}{ ( } \\
Previous fracture & 3899 & 756 & 209 & 97 & 55 & 34 \\
No fracture 101578 & 19776 & 5735 & 2856 & 1610 & 962
\end{tabular}

the left shows data for women with a known chronic disease requiring long-term treatment $(N=44,028)$. The figure to the right includes all women starting GC treatment $(N=105,477)$ 


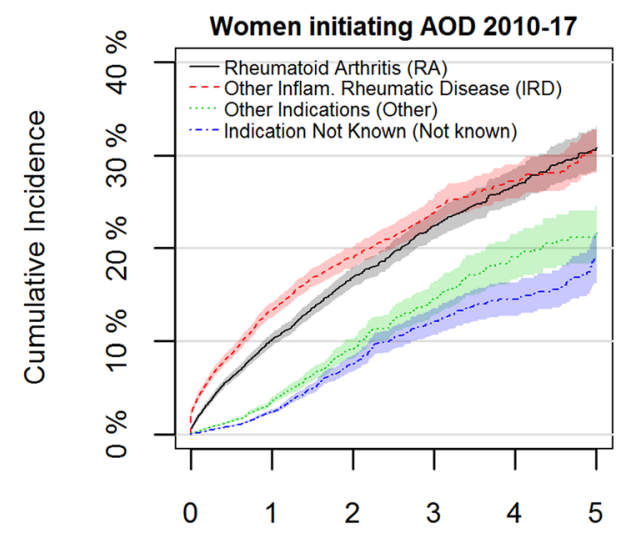

Time (years)

\begin{tabular}{rlllll} 
Number at risk (N) & \multicolumn{3}{c}{ (N) } \\
RA 9543 & 4361 & 1910 & 992 & 543 & 314 \\
IRD 9147 & 3599 & 1552 & 801 & 477 & 287 \\
Other 25338 & 4734 & 1043 & 486 & 263 & 156 \\
Not Known 61449 & 7838 & 1439 & 674 & 382 & 239
\end{tabular}

Fig. 3 Cumulative incidence (with 95\% confidence bands) of women 55-84 years in Norway of starting treatment with anti-osteoporotic drugs (AOD) after initiation of glucocorticoid (GC) treatment 2010-

without fracture, and this association was strongest among women with no known indication for GC treatment $(\mathrm{HR}=$ 2.6) and in the group "other GC indication" (chronic obstructive lung disease, asthma, sarcoidosis, dermatitis, and ulcerative colitis) $(H R=2.4)$. Overall, women with a diagnosis of inflammatory rheumatic disease were 2-3 times more likely to start treatment with AOD within the first year compared with

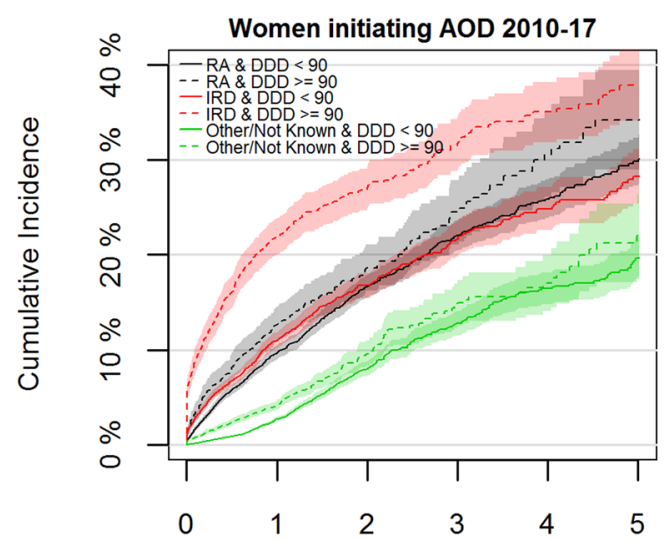

Time (years)

\begin{tabular}{|c|c|c|c|c|c|c|}
\hline \multicolumn{7}{|c|}{ Number at risk $(\mathrm{N})$} \\
\hline RA \& DDD $<90$ & 8214 & 3475 & 1525 & 801 & 437 & 259 \\
\hline RA \& DDD > $=90$ & 1329 & 886 & 385 & 191 & 106 & 55 \\
\hline IRD \& DDD < 90 & 7288 & 2447 & 1056 & 524 & 320 & 187 \\
\hline$D \& D D D>=90$ & 1859 & 1152 & 496 & 277 & 157 & 100 \\
\hline$N n \& D D D<90$ & 79430 & 8024 & 1955 & 925 & 526 & 318 \\
\hline $\mathrm{vn} \& \mathrm{DDD}>=90$ & 7357 & 4548 & 527 & 235 & 119 & 77 \\
\hline
\end{tabular}

2016, stratified by GC indication (left) and by initial Defined Daily Dose of GC and GC indication (right)

women without this condition. Further, women given an initial dose of GC of more than 90 DDD were more than twice as likely to start AOD treatment within 1 year than women given less than 90 DDD, both for women with and without previous fracture. However, the vast majority of women on GC treatment were initially prescribed less than 90 DDD, and a large proportion of these continued GC treatment beyond 1 year,

Table 2 Age-standardized incidence rates and risk (HR) of initiating anti-osteoporotic drugs (previous fracture vs. no previous fracture) in 105,477 Norwegian women (55-84 years old) initiating glucocorticoid (GC) treatment in the period 2010-2016

\begin{tabular}{|c|c|c|c|c|c|}
\hline & \multicolumn{2}{|c|}{ No previous fracture } & \multicolumn{2}{|l|}{ Previous fracture } & \multirow[b]{2}{*}{ Adj. $\mathrm{HR}^{2}(95 \% \mathrm{CI})$} \\
\hline & $N /$ person years & Adj. $\mathrm{IR}^{1}$ & $N /$ person years & Adj. $\mathrm{IR}^{1}$ & \\
\hline All women initiating GC & $3004 / 70,264$ & $4.2(4.1,4.4)$ & $257 / 2645$ & $9.0(7.9,10.3)$ & $2.0(1.8,2.3)$ \\
\hline \multicolumn{6}{|l|}{ Indication for $\mathrm{GC}^{3}$} \\
\hline Rheumatoid arthritis & $788 / 7245$ & $10.3(9.5,11.1)$ & $53 / 283$ & $16.3(11.2,24.4)$ & $1.6(1.2,2.1)$ \\
\hline Other inflammatory rheumatic disease & $981 / 6471$ & $14.4(13.5,15.4)$ & $79 / 331$ & $21.8(16.9,28.0)$ & $1.5(1.2,1.9)$ \\
\hline Other Indications & $491 / 16,804$ & $2.9(2.7,3.2)$ & $59 / 774$ & $7.8(5.8,10.3)$ & $2.4(1.8,3.2)$ \\
\hline Indication not known & $744 / 39,744$ & $1.9(1.8,2.0)$ & $66 / 1257$ & $5.1(3.9,6.6)$ & $2.6(2.0,3.4)$ \\
\hline \multicolumn{6}{|c|}{ Number of Defined Daily Doses dispensed of GC at initiation of GC } \\
\hline$<90 \mathrm{DDD}$ & $2208 / 61,495$ & $3.5(3.4,3.7)$ & $198 / 2297$ & $7.7(6.6,9.0)$ & $2.2(1.9,2.5)$ \\
\hline$>=90 \mathrm{DDD}$ & $796 / 8769$ & $8.9(8.3,9.5)$ & $59 / 347$ & $18.3(13.7,24.2)$ & $1.7(1.3,2.2)$ \\
\hline
\end{tabular}

$H R$ hazard ratio, $I R$ incidence rates, $D D D$ Defined Daily Doses

All women initiating GC by indication for GC use and by number of Defined Daily Doses of GC dispensed at initiation of GC 1-year follow-up

${ }^{1}$ Age-standardized incidence rates per 100 person years

2 "No previous fracture" as reference. Adjusted for age at initiation of GC, index year, and education

${ }^{3}$ Based on reimbursement codes at first GC dispensing (NorPD) or on diagnostics codes (ICD-10) in the 2-year baseline period (NPR) 
Fig. 4 Age-standardized incidence rates with $95 \%$ confidence intervals of starting with anti-osteoporotic drugs (AOD) within 1 year after initiating glucocorticoid (GC) treatment by type of GC indication, as a function of year of initiating GC treatment

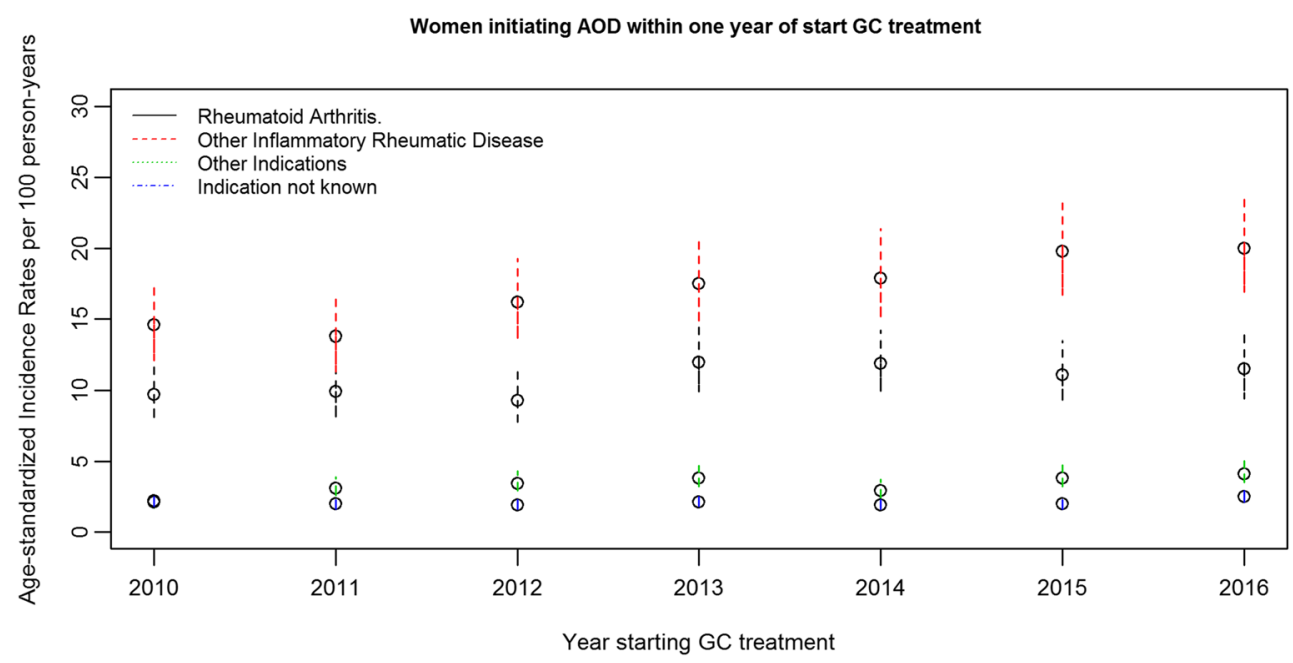

which may suggest that AOD treatment should have been initiated. During the years 2010 to 2016, the rate of AOD prescribed to those initiating GC increased on average $3 \%$ per year, and this positive trend was higher among women with $(10 \%)$ versus without (3\%) previous fracture, as well as among women with other indications for GC treatment (7\%), compared with women with inflammatory rheumatic disease (3-4\%).

\section{Earlier fracture and fracture risk/undertreatment}

According to both previous and current guidelines, patients with previous fractures as well as those receiving GC therapy for more than 3 months are at a high risk for fractures, and AOD should be considered $[10,12]$. The present study found that women with a recent fracture who initiated GC treatment subsequently started AOD treatment almost twice as often as those without a previous fracture. Women in the fracture cohort were older and had more comorbidity than those without recent fractures; thus, the proportion starting AOD should be high. However, the AOD treatment rates were low, even in this group. It is worth noticing that among women starting AOD, the median time from starting $\mathrm{GC}$ to prescribing AOD was more than 1 year, both among those with and without previous fractures. Low treatment rates in high-risk patients have also been reported in a Danish study, where only $1 / 3$ of the hip fracture patients started AOD during the subsequent year [36].

Reimbursement rules have been important for choice of AOD and decisions concerning whom to treat. In Norway, osteoporosis confirmed by a BMD measurement was required between 2006 and 2011 , excluding those living in rural areas without any available device for BMD measurements. In addition, up to 2012, AOD were only fully reimbursed after a fracture [15]. Thus, women without a previous fracture or who did not have a BMD-verified osteoporosis diagnosis had to pay the full costs for the AOD treatment. This may explain the low AOD treatment rate in women initiating $\mathrm{GC}$ without a previous fracture. Reimbursement for corticosteroid-induced osteoporosis was introduced in 2013.

In our nationwide cohort, around $10 \%$ of women with a recent fracture were on AOD after 1 year (incident use) from GC initiation. In a community study in Central Norway among women 50-85 years old with a $>20 \%$ estimated 10 year risk of sustaining a major osteoporotic fracture, only $25 \%$ were treated with AOD, further illustrating the level of undertreatment [37]. There is, however, increased attention to some risk factors, and long-term use of GC in combination with sustaining a hip fracture was the strongest predictor for starting AOD in another Norwegian study [38].

A Canadian study found that women who started taking GC and who had a previous fracture were more often admitted to BMD measurements or to receive AOD than those without a fracture [39]. A French study reported that $26 \%$ of women above 55 years starting GC were treated with osteoporosis medication, which also included those who only started supplements of calcium and vitamin D [40]. Thus, the proportion on AOD was even lower.

\section{Inflammatory rheumatic diseases}

In our study, women with a diagnosis of an inflammatory rheumatic disease were more likely to start AOD treatment within 1 year from GC initiation, compared with women with other diagnoses, even without having had a recent fracture. Studies from Norway, the USA, and France have found that rheumatologists refer patients on GC treatment to BMD measurements and start AOD more frequently than other specialists [38, 40, 41]. The American College of Rheumatology published guidelines for prevention and treatment of GCinduced osteoporosis as early as in 1996, and the awareness about inflammation, as well as GC, as a contributing factor to osteoporosis is high among rheumatologists [42-45]. Equipment for measuring BMD is often allocated to rheumatologic practices, which lowers the threshold for identifying 
those at risk and starting osteoporosis prophylaxis and treatment. Despite this, a recent French study investigating whether the guidelines for prevention of GC-induced osteoporosis were applied in patients with RA found that less than $30 \%$ of those with an indication for treatment received AOD [46]. Guidelines may not be sufficient, and a Japanese group decided to increase education and attention to GC-induced osteoporosis at their hospital by introducing a quality indicator to monitor prevention and treatment of GC-induced osteoporosis [47]. They found that these interventions improved the proportion of patients treated with AOD during 2010-2013.

Only a few women with SLE were included in the present study, and none of these was registered with a fracture. The incidence of SLE is low in this age group, and thereby few start GC treatment- thus, most women 55 years and older with SLE had already started using GC when they were younger and were therefore not eligible for inclusion (i.e. they were not incident users). In a Spanish study including 576 women with RA or SLE using long-term GC, 19\% had radiologically confirmed vertebral fracture. The prevalent use of AOD was about 50\% for the total cohort and about $80 \%$ for those with a radiologically confirmed vertebral fracture [48]. This may indicate that many patients with rheumatic disease on GC start AOD treatment eventually, but preventive treatment may be delayed.

Most patients with PMR/GCA are treated with GC for several months or years, and AOD would be indicated. The majority of patients with inflammatory disease other than RA in our study had PMR/GCA, and this group had the highest HR for starting AOD treatment (adjusted for age). In a Danish study, only half of the cohort with PMR/GCA were treated with AOD even though this is a high-risk population with median age 73 years and a majority of women [49].

\section{Trends}

We found that AOD was increasingly dispensed to women initiating GC during the years 2010 to 2016, especially from 2013 when bisphosphonates were reimbursed for corticosteroidinduced osteoporosis. However, this reimbursement was only for $10 \mathrm{mg}$ alendronate in daily oral administration, not for the much more frequently prescribed weekly administration. In an earlier Norwegian study, a decrease in the initiation of AOD was found during 2004-2007 for a population above 40 years [17]. In the previously mentioned study from Central Norway, the rate of initiation of AOD after a forearm fracture did not change between 2005 and 2012 [15]. Our finding is consistent with an increased awareness of the negative effects of GC on the bone as the AOD treatment rate increased over time in GC starters. Our finding is in concordance with the Canadian study reporting a $51 \%$ increase in GC-induced osteoporosis preventive care (including both BMD testing and AOD prescribing) in new users of GC during the years 1998-2008 [39].

\section{Limitations/strengths}

The strength of this study is the nationwide cohort of all Norwegian women 55-85 years old and the long follow-up time. We aimed to describe to which degree AOD was dispensed to women initiating GC therapy, thereby focusing more on the attentiveness of the physicians to antiosteoporotic treatment rather than the patients' adherence to treatment. As in all studies based on pharmacy-dispensed medications, the actual number prescribed maybe higher than the number dispensed, in which case the dispensing rates will underestimate the actual prescribing rates. Further, we cannot know whether the medication dispensed was actually taken. Some information on the use of intravenously administered bisphosphonates may be lacking, as medications administered in hospitals and nursing homes are not registered in the NorPD. Using hospital data on intravenously administered bisphosphonates (Zoledronic acid) and indication (excluding cancer diagnosis), both obtained from the NPR, suggests that the use of AOD is underestimated with about $5 \%$.

We also lack information about treatment with AOD before the look-back period of 5 year, and some of the patients may have been on a "drug holiday" after long-term treatment with AOD and not considered eligible for starting AOD again. The patient's motivation is also important for AOD treatment; the treating physician may have considered AOD and decided not to start due to comorbidity or patient's resistance to therapy. There may be some slight under-reporting of fractures, as only fractures registered in hospital in- and outpatient clinics and emergency departments, and not those treated only by the general practitioner, are included in the Norwegian Patient Registry.

As $14.5 \%$ of those without a fracture in our study population were on HRT before initiating GC, this may have been one reason for not starting AOD. HRT has been found to be a negative predictor for starting AOD in an earlier study [15].

Bone mineral density data are not available in the national registry data such as those used in our study, and this represents a limitation. At the population level, the majority of women in this age group have either osteoporosis or osteopenia and should therefore be eligible for osteoporosis prophylaxis when starting GC treatment had bone mineral density been measured.

We used 180 days as the allowable treatment gap before censoring GC patients. Therefore, the number still on GC treatment and at risk of starting AOD the first year after treatment may be artificially high, compared with if we had used a smaller treatment gap, such as 90 days. On the other hand, when using 180 days as the allowable treatment gap, we increased the number at risk 2-4 times, depending on GC indication and follow-up time, compared with using 90 days as the treatment gap. 


\section{Conclusion}

Although postmenopausal women starting long-term GC treatment are at a high risk of fracture, the majority did not start treatment with AOD following GC initiation. The probability of starting AOD was especially low for women initiating GC with no reported indication for this treatment. However, we did observe a slight increase in AOD, within 1-year treatment rates, for women initiating GC from 2010 to 2016 and especially from 2013 when AOD reimbursement for corticosteroidinduced osteoporosis became available. Women with a previous fracture or who had an inflammatory rheumatic disease were more frequently treated with AOD after initiating GC, but even in these groups the recommendations in guidelines for osteoporosis prophylaxis were often not followed. The bone harming effect of GC may not be fully appreciated by physicians, and better routines for prevention of $\mathrm{GC}$-induced osteoporosis and fractures should be established. Further, reimbursement rules should better reflect the international guidelines not only for osteoporosis treatment but also for prophylaxis.

Authors' contributions EMA, GST, and AL designed the study. EMA and $\mathrm{AL}$ analyzed and interpreted the results. EMA drafted the manuscript, and GST, MH, VE, and AL critically revised and improved the manuscript.

Funding information Open Access funding provided by University of Bergen.

\section{Compliance with ethical standards}

Conflicts of interest Astrid Lunde is involved in the Denosumab Global Safety Study (Amgen protocol 20090522; Amgen Inc., Thousand Oaks). Department of Clinical Epidemiology, Aarhus University receives an institutional research funding from several pharmaceutical companies, some of which manufacture AOD. None of these companies was involved in the current study. Vera Ehrenstein is a salaried employee of the Aarhus University. Ellen M. Apalset, Mari Hoff, and Grethe S. Tell declare that they have no conflict of interest.

Ethics approval Data from the Denosumab Global Safety Study was used in this study, with approval from the Norwegian Data Protection Agency (ref. 11/00192-5) and from the ethics committee (ref. 2010/2616-2).

Disclaimer "Data from the Norwegian Patient Register have been used in this publication. The interpretation and reporting of these data are the sole responsibility of the authors, and no endorsement by the Norwegian Patient Register is intended nor should be inferred."

Open Access This article is licensed under a Creative Commons Attribution 4.0 International License, which permits use, sharing, adaptation, distribution and reproduction in any medium or format, as long as you give appropriate credit to the original author(s) and the source, provide a link to the Creative Commons licence, and indicate if changes were made. The images or other third party material in this article are included in the article's Creative Commons licence, unless indicated otherwise in a credit line to the material. If material is not included in the article's Creative Commons licence and your intended use is not permitted by statutory regulation or exceeds the permitted use, you will need to obtain permission directly from the copyright holder. To view a copy of this licence, visit http://creativecommons.org/licenses/by/4.0/.

\section{References}

1. Fardet L, Petersen I, Nazareth I (2011) Prevalence of long-term oral glucocorticoid prescriptions in the UK over the past 20 years. Rheumatology (Oxford) 50(11):1982-1990. https://doi.org/10. 1093/rheumatology/ker017

2. Mazziotti G, Angeli A, Bilezikian JP, Canalis E, Giustina A (2006) Glucocorticoid-induced osteoporosis: an update. Trends Endocrinol Metab 17(4):144-149. https://doi.org/10.1016/j.tem. 2006.03.009

3. Kanis JA, Johansson H, Oden A, Johnell O, de Laet C, Melton IL, Tenenhouse A, Reeve J, Silman AJ, Pols HA, Eisman JA, McCloskey EV, Mellstrom D (2004) A meta-analysis of prior corticosteroid use and fracture risk. J Bone Miner Res 19(6):893-899

4. Angeli A, Guglielmi G, Dovio A, Capelli G, de Feo D, Giannini S, Giorgino R, Moro L, Giustina A (2006) High prevalence of asymptomatic vertebral fractures in post-menopausal women receiving chronic glucocorticoid therapy: a cross-sectional outpatient study. Bone 39(2):253-259. https://doi.org/10.1016/j.bone.2006.02.005

5. Curtis JR, Westfall AO, Allison J, Bijlsma JW, Freeman A, George V, Kovac SH, Spettell CM, Saag KG (2006) Population-based assessment of adverse events associated with long-term glucocorticoid use. Arthritis Rheum 55(3):420-426. https://doi.org/10.1002/ art. 21984

6. Amiche MA, Albaum JM, Tadrous M, Pechlivanoglou P, Levesque LE, Adachi JD, Cadarette SM (2016) Fracture risk in oral glucocorticoid users: a Bayesian meta-regression leveraging control arms of osteoporosis clinical trials. Osteoporos Int 27(5):1709-1718. https://doi.org/10.1007/s00198-015-3455-9

7. Laan RF, van Riel PL, van de Putte LB, van Erning LJ, van't Hof MA, Lemmens JA (1993) Low-dose prednisone induces rapid reversible axial bone loss in patients with rheumatoid arthritis. A randomized, controlled study. Ann Intern Med 119(10):963-968

8. Van Staa TP, Leufkens HG, Abenhaim L, Zhang B, Cooper C (2000) Use of oral corticosteroids and risk of fractures. J Bone Miner Res 15(6):993-1000. https://doi.org/10.1359/jbmr.2000.15. 6.993

9. Van Staa TP, Laan RF, Barton IP, Cohen S, Reid DM, Cooper C (2003) Bone density threshold and other predictors of vertebral fracture in patients receiving oral glucocorticoid therapy. Arthritis Rheum 48(11):3224-3229. https://doi.org/10.1002/art.11283

10. Compston J, Cooper A, Cooper C, Gittoes N, Gregson C, Harvey N, Hope S, Kanis JA, McCloskey EV, Poole KES, Reid DM, Selby P, Thompson F, Thurston A, Vine N, National Osteoporosis Guideline G (2017) UK clinical guideline for the prevention and treatment of osteoporosis. Arch Osteoporos 12(1):43. https://doi. org/10.1007/s11657-017-0324-5

11. Buckley L, Guyatt G, Fink HA, Cannon M, Grossman J, Hansen KE, Humphrey MB, Lane NE, Magrey M, Miller M, Morrison L, Rao M, Byun Robinson A, Saha S, Wolver S, Bannuru RR, Vaysbrot E, Osani M, Turgunbaev M, Miller AS, McAlindon T (2017) 2017 American College of Rheumatology Guideline for the prevention and treatment of glucocorticoid-induced osteoporosis. Arthritis Care Res 69(8):1095-1110. https://doi.org/10.1002/ acr.23279 
12. Compston J (2004) US and UK guidelines for glucocorticoidinduced osteoporosis: similarities and differences. Curr Rheumatol Rep 6(1):66-69

13. Rheumatology NSo (2018) Osteoporosis: investigation, treatment and follow-up 2015. https://www.legeforeningen.no/contentassets/ 17680701898944129b38d3540d917518/osteoporose-2018.pdf

14. Devold HM, Furu K, Skurtveit S, Tverdal A, Falch JA, Sogaard AJ (2012) Influence of socioeconomic factors on the adherence of alendronate treatment in incident users in Norway. Pharmacoepidemiol Drug Saf 21(3):297-304. https://doi.org/10. $1002 /$ pds. 2344

15. Hoff M, Skurtveit S, Meyer HE, Langhammer A, Sogaard AJ, Syversen U, Abrahamsen B, Schei B (2015) Use of antiosteoporotic drugs in Central Norway after a forearm fracture. Arch Osteoporos 10:235. https://doi.org/10.1007/s11657-0150235-2

16. Hernlund E, Svedbom A, Ivergard M, Compston J, Cooper C, Stenmark J, McCloskey EV, Jonsson B, Kanis JA (2013) Osteoporosis in the European Union: medical management, epidemiology and economic burden. A report prepared in collaboration with the international Osteoporosis foundation (IOF) and the European Federation of Pharmaceutical Industry Associations (EFPIA). Arch Osteoporos 8(1-2):136. https://doi.org/10.1007/ s11657-013-0136-1

17. Devold HM, Doung GM, Tverdal A, Furu K, Meyer HE, Falch JA, Sogaard AJ (2010) Prescription of anti-osteoporosis drugs during 2004-2007-a nationwide register study in Norway. Eur J Clin Pharmacol 66(3):299-306. https://doi.org/10.1007/s00228-0090746-0

18. Haugeberg G, Hansen IJ, Soldal DM, Sokka T (2015) Ten years of change in clinical disease status and treatment in rheumatoid arthritis: results based on standardized monitoring of patients in an ordinary outpatient clinic in southern Norway. Arthritis Res Ther 17: 219. https://doi.org/10.1186/s13075-015-0716-0

19. Makol A, Davis JM 3rd, Crowson CS, Therneau TM, Gabriel SE, Matteson EL (2014) Time trends in glucocorticoid use in rheumatoid arthritis: results from a population-based inception cohort, 1980-1994 versus 1995-2007. Arthritis Care Res 66(10):14821488. https://doi.org/10.1002/acr.22365

20. Guler-Yuksel M, Bijsterbosch J, Goekoop-Ruiterman YP, de VriesBouwstra JK, Hulsmans HM, de Beus WM, Han KH, Breedveld FC, Dijkmans BA, Allaart CF, Lems WF (2008) Changes in bone mineral density in patients with recent onset, active rheumatoid arthritis. Ann Rheum Dis 67(6):823-828. https://doi.org/10.1136/ $\operatorname{ard} .2007 .073817$

21. Haugeberg G, Strand A, Kvien TK, Kirwan JR (2005) Reduced loss of hand bone density with prednisolone in early rheumatoid arthritis: results from a randomized placebo-controlled trial. Arch Intern Med 165(11):1293-1297. https://doi.org/10.1001/archinte.165.11. 1293

22. Kanis JA, Oden A, Johansson H, Borgstrom F, Strom O, McCloskey E (2009) FRAX and its applications to clinical practice. Bone 44(5):734-743. https://doi.org/10.1016/j.bone.2009.01.373

23. Cooper C, Bardin T, Brandi ML, Cacoub P, Caminis J, Civitelli R, Cutolo M, Dere W, Devogelaer JP, Diez-Perez A, Einhorn TA, Emonts P, Ethgen O, Kanis JA, Kaufman JM, Kvien TK, Lems WF, McCloskey E, Miossec P, Reiter S, Ringe J, Rizzoli R, Saag K, Reginster JY (2016) Balancing benefits and risks of glucocorticoids in rheumatic diseases and other inflammatory joint disorders: new insights from emerging data. An expert consensus paper from the European Society for Clinical and Economic Aspects of Osteoporosis and Osteoarthritis (ESCEO). Aging Clin Exp Res 28(1):1-16. https://doi.org/10.1007/s40520-015-0522-1

24. Rossini M, Viapiana O, Vitiello M, Malavolta N, La Montagna G, Maddali Bongi S, Di Munno O, Nuti R, Manzini CU, Ferri C, Bogliolo L, Mathieu A, Cantatore F, Del Puente A, Muratore M,
Grassi W, Frediani B, Saviola G, Delvino P, Mirone L, Ferraccioli G, Tripi G, Piazza I, Gatti D (2017) Prevalence and incidence of osteoporotic fractures in patients on long-term glucocorticoid treatment for rheumatic diseases: the Glucocorticoid Induced OsTeoporosis TOol (GIOTTO) study. Reumatismo 69(1):30-39. https://doi.org/10.4081/reumatismo.2017.922

25. Naranjo A, Lopez R, Garcia-Magallon B, Caceres L, Francisco F, Jimenez-Palop M, Ojeda-Bruno S (2014) Longitudinal practice patterns of prophylaxis of glucocorticoid-induced osteoporosis in patients with polymyalgia rheumatica. Rheumatol Int 34(10):1459 1463. https://doi.org/10.1007/s00296-014-3014-2

26. National Registry of Norway https://www.skatteetaten.no/en/ Person/National-Registry

27. Norwegian Prescription Database (NorPD) http://www.norpd.no

28. Furu K (2009) Establishment of the nationwide Norwegian Prescription Database (NorPD) - new opportunities for research in pharmacoepidemiology in Norway. Norsk Epidemiologi 18(2). https://doi.org/10.5324/nje.v18i2.23

29. Norwegian Patient Registry (NPR) https://helsedirektoratet.no/ english

30. The Norwegian Cause of Death Registry https://www.fhi.no/en/hn/ health-registries/cause-of-death-registry

31. Individually Based Education Statistics Documentation (2005) Statistics Norway https://www.ssb.no/a/english/publikasjoner/pdf/ nos_d361_en/nos_d361_en.pdf

32. Nilssen Y, Strand TE, Wiik R, Bakken IJ, Yu XQ, O'Connell DL, Moller B (2014) Utilizing national patient-register data to control for comorbidity in prognostic studies. Clin Epidemiol 6:395-404. https://doi.org/10.2147/clep.s70742

33. Pedersen AG, Ellingsen CL (2015) Data quality in the causes of death registry. Tidsskr Nor Laegeforen 135(8):768-770. https://doi. org/10.4045/tidsskr.14.1065

34. Schneeweiss S, Wang PS, Avorn J, Glynn RJ (2003) Improved comorbidity adjustment for predicting mortality in Medicare populations. Health Serv Res 38(4):1103-1120

35. Igland J, Vollset SE, Nygard OK, Sulo G, Sulo E, Ebbing M, Naess O, Ariansen I, Tell GS (2014) Educational inequalities in 28 day and 1-year mortality after hospitalisation for incident acute myocardial infarction-a nationwide cohort study. Int J Cardiol 177(3):874 880. https://doi.org/10.1016/j.ijcard.2014.10.045

36. Kristensen PK, Ehrenstein V, Shetty N, Pedersen AB (2019) Use of anti-osteoporosis medication dispensing by patients with hip fracture: could we do better? Osteoporos Int 30(9):1817-1825. https:// doi.org/10.1007/s00198-019-05066-8

37. Hoff M, Skurtveit S, Meyer HE, Langhammer A, Sogaard AJ, Syversen U, Skovlund E, Abrahamsen B, Forsmo S, Schei B (2018) Anti-osteoporosis drug use: too little, too much, or just right? The HUNT study, Norway. Osteoporos Int 29:1875-1885. https://doi.org/10.1007/s00198-018-4560-3

38. Devold HM, Sogaard AJ, Tverdal A, Falch JA, Furu K, Meyer HE (2013) Hip fracture and other predictors of anti-osteoporosis drug use in Norway. Osteoporos Int 24(4):1225-1233. https://doi.org/ 10.1007/s00198-012-2063-1

39. Majumdar SR, Lix LM, Yogendran M, Morin SN, Metge CJ, Leslie WD (2012) Population-based trends in osteoporosis management after new initiations of long-term systemic glucocorticoids (19982008). J Clin Endocrinol Metab 97(4):1236-1242. https://doi.org/ 10.1210/jc.2011-2645

40. Trijau S, de Lamotte G, Pradel V, Natali F, Allaria-Lapierre V, Coudert H, Pham T, Sciortino V, Lafforgue P (2016) Osteoporosis prevention among chronic glucocorticoid users: results from a public health insurance database. RMD Open 2(2): e000249. https://doi.org/10.1136/rmdopen-2016-000249

41. Saag KG, Gehlbach SH, Curtis JR, Youket TE, Worley K, Lange JL (2006) Trends in prevention of glucocorticoid-induced osteoporosis. J Rheumatol 33(8):1651-1657 
42. (1996) Recommendations for the prevention and treatment of glucocorticoid-induced osteoporosis. American College of Rheumatology Task Force on Osteoporosis Guidelines. Arth Rheum 39(11):1791-801. https://doi.org/10.1002/art.1780391104

43. Kan SL, Yuan ZF, Li Y, Ai J, Xu H, Sun JC, Feng SQ (2016) Alendronate prevents glucocorticoid-induced osteoporosis in patients with rheumatic diseases: a meta-analysis. Medicine (Baltimore) 95(25):e3990. https://doi.org/10.1097/MD. 0000000000003990

44. van der Goes MC, Jacobs JW, Boers M, Andrews T, Blom-Bakkers MA, Buttgereit F, Caeyers N, Cutolo M, Da Silva JA, Guillevin L, Kirwan JR, Rovensky J, Severijns G, Webber S, Westhovens R, Bijlsma JW (2010) Monitoring adverse events of low-dose glucocorticoid therapy: EULAR recommendations for clinical trials and daily practice. Ann Rheum Dis 69(11):1913-1919. https://doi.org/ 10.1136/ard.2009.124958

45. Wall E, Walker-Bone K (2008) Use of bisphosphonates and dualenergy X-ray absorptiometry scans in the prevention and treatment of glucocorticoid-induced osteoporosis in rheumatology. QJM 101(4):317-323. https://doi.org/10.1093/qjmed/hom126

46. Malochet-Guinamand S, Lambert C, Gossec L, Soubrier M, Dougados M (2019) Evaluation of the implementation of guidelines on the treatment of osteoporosis in patients with rheumatoid arthritis. J Rheumatol 47:6-14. https://doi.org/10.3899/jrheum. 180889

47. Suda M, Suyama Y, Ohde S, Tsuda T, Sawada H, Kishimoto M, Okada M (2018) Effects of quality indicator monitoring for glucocorticoid-induced osteoporosis and trends of drug treatment in a Japanese hospital. Int J Rheum Dis 21(5):975-981. https://doi. org/10.1111/1756-185x.13310

48. Rentero ML, Amigo E, Chozas N, Fernandez Prada M, SilvaFernandez L, Abad Hernandez MA, Rodriguez Barrera JM, del Pino-Montes J, group Gs (2015) Prevalence of fractures in women with rheumatoid arthritis and/or systemic lupus erythematosus on chronic glucocorticoid therapy. BMC Musculoskelet Disord 16: 300. https://doi.org/10.1186/s12891-015-0733-9

49. Emamifar A, Gildberg-Mortensen R, Andreas Just S, Lomborg N, Asmussen Andreasen R, Jensen Hansen IM (2015) Level of adherence to prophylactic osteoporosis medication amongst patients with polymyalgia rheumatica and giant cell arteritis: a cross-sectional study. Int J Rheumatol 2015:783709-783705. https://doi.org/10. $1155 / 2015 / 783709$

Publisher's note Springer Nature remains neutral with regard to jurisdictional claims in published maps and institutional affiliations. 